\title{
Movimentos sociais e a formação política de mulheres na luta por creches: a experiência do "Artcreche" em São Gonçalo
}

\begin{abstract}
Resumo: O artigo objetiva inventariar e atualizar a luta de Movimentos Sociais urbanos, em especial do Movimento de Articulação das Creches de São Gonçalo (ArtCreche) que desde 1980 vem construindo uma pauta coletiva de demandas e lutas junto ao poder público e Sociedade civil em São Gonçalo. Do ponto de vista teórico-conceitual, enfocamos a luta do ArtCreche a partir do diálogo com autores/as que fazem alusão à eclosão dos movimentos populares na década de 1980, bem como ao seu refluxo no período de pós-democratização brasileira, e que remetem ao contexto de mudanças frente aos paradigmas clássicos e contemporâneos de participação popular. No artigo investigamos a luta de mulheres pelo direito à creche a partir de uma pesquisa qualitativa, de cunho participante, que intenciona investigar o trabalho cotidiano e as lutas de um grupo de educadoras populares do Movimento ARTCreche, a partir da realização de entrevistas semi-estruturadas, priorizando uma análise do poder local em diálogo com lutas contemporâneas pelo direito à creche nas periferias urbanas.
\end{abstract}

Palavras-chave: Movimentos Sociais Urbanos. Lutas de Mulheres. Creches Comunitárias. Movimento Artcreche.

\section{Social movements and the political formation of women in the fight for day care: the experience of "Artcreche" in São Gonçalo}

Abstract: The article aims to inventory and update the struggle of urban social movements, especially the São Gonçalo Daycare Center (ArtCreche), which since 1980 has been building a collective agenda of demands and struggles with public power and civil society in São Gonçalo. From a theoretical-conceptual point of view, we focus on ArtCreche's struggle through dialogue with authors who refer to the outbreak of popular movements in the 1980s, as well as their ebb in the postdemocratization period in Brazil, to the context of changes facing the classic and contemporary paradigms of popular participation. In the article we investigate the struggle of women for the right to day care based on a qualitative, participatory research, that intends to investigate the daily work and struggles of a group of popular educators of the ARTCreche Movement, based on semi-structured interviews , prioritizing an analysis of local power in dialogue with contemporary struggles for the right to day care in the urban peripheries.

Keywords: Urban Social Movements. Women's Fights. Community Day Care Centers. Artcreche Movement.

\footnotetext{
1 Doutora em Educação pela Universidade Federal do Rio de Janeiro. Professora Associada da Universidade do Estado do Rio de Janeiro (UERJ). Professora do Programa de Pós-Graduação Mestrado em Educação Processos Formativos e Desigualdades SociaisFFP/UERJ. E-mail: mtgtavares@yahoo.com.br
} 


\section{Introdução}

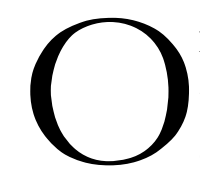

presente artigo, que é fruto de uma pesquisa ainda em desenvolvimento, objetiva inventariar e atualizar a luta de Movimentos de Mulheres por creche, em especial, das mulheres que constituem o Movimento de Articulação das Creches - ArtCreche, que vem atuando em São Gonçalo, na região metropolitana do Estado do Rio de Janeiro. Do ponto de vista teórico metodológico, fundamentada em trabalhos anteriores, vimos optando pela pesquisa qualitativa de natureza etnográfica e participativa ( BRANDÃO, 2003), na qual a pesquisa é concebida como uma experiência de conhecimento, e o trabalho de campo, longe de ser apenas um trabalho de coleta e produção de dados, de conhecimentos e questões, nos possibilita um movimento de ação-reflexão-ação coletiva sobre o(s) processo(s) de produção do conhecimento, corroborando o que Santos defende como o papel político e epistêmico da pesquisa numa perspectiva emancipatória(SANTOS, 2000). Nesse percurso, provocada pela força política, pedagógica e discursiva da(s) longa(s) luta(s) de mulheres do ArtCreche, assumimos no presente artigo, o pressuposto conceitual e político de que uma teoria é um dispositivo analítico para melhor conhecer o que ainda não sabemos, e também para produzir estranbamentos naquilo que se apresenta com familiar, como por exemplo, o descaso dos poderes públicos com a (re)produção da vida das classes populares nos diferentes territórios da cidade. Isto posto, do ponto de vista metodológico e dos procedimentos de produção dos dados da pesquisa ainda em realização, temos priorizado o trabalho de campo junto a um grupo de cinco (5) creches comunitárias no município de São Gonçalo, priorizando a partir de entrevistas semiestruturadas, a escuta atenta das diferentes vozes de educadoras populares que atuam nesses espaços, buscando compreender diferentes nexos de suas lutas pelo direito à creche na cidade.

Do ponto de vista contextual e de sua ação política, desde 1980, o movimento ArtCrechevem construindo uma pauta de demandas e lutas junto ao poder público e Sociedade civil em São Gonçalo, uma das três maiores cidades do Estado do Rio de janeiro e a décima quarta metrópole do Brasil, e que apresenta um enorme contingente de crianças de 0 a 3 anos, das quais apenas $5 \%$ estão inseridas em algum tipo de equipamento público e/ou conveniado de educação infantil, especialmente em creches públicas.

Estas questões demarcam o pano de fundo estrutural e conjuntural no qual as lutas do movimento ArtCreche se tornam emergentes em São Gonçalo. Este cenário, embora apresentado de forma breve, nos mostra que a construção e implementação de políticas públicas de educação em contextos periféricos, os seus desafios, com avanços e dificuldades que hoje se apresentam na busca pela justiça social e pelo direito à educação, tem sido fruto de lutas acirradas entre diferentes atores, produzindo tensões entre as diferentes escalas de poder político e econômico, em especial nos bairros periféricos das grandes metrópoles brasileiras. 
Neste sentido, problematizar algumas questões e atravessamentos presentes na relação entre movimentos sociais e o direito à educação $\mathrm{da}(\mathrm{s})$ infância(s) numa metrópole periférica do Leste Fluminense, se apresenta como uma das principais intenções do texto, nos exigindo uma maior contextualização dos conceitos e noções utilizados na construção do arcabouço teórico e metodológico do artigo em tela, como opor exemplo, o conceito de "Movimentos Sociais".

Segundo a pesquisadora Magali Alonso (2009), do ponto de vista das Ciências Sociais, o termo "movimentos sociais" foi criado no início dos anos sessenta do século passado, com vistas a nomear multidões que se manifestavam nas ruas exigindo mudanças pacíficas ("faça amor, não faça a guerra"), aparentemente desinteressadas de pressionar o Estado por algum tipo de poder. Nessa perspectiva, o termo movimentos sociais vêm assumindo nas últimas cinco décadas diferentes significados e sentidos, fundamentados em distintas teorias (TOURAINE, 1977; MELLUCI, 1989; GOHN, 2010; ALONSO, 2009 e TARROW, 2009).

Ainda segundo Alonso (2009), tais teorias construíram os seus principais fundamentos políticos e epistêmicos em oposição à teoria marxista, à concepção de revolução social, ao protagonismo das classes trabalhadoras, e do operariado urbano. Para esta autora (idem), as configurações destes movimentos, os modos de luta e os seus repertórios de ação buscariam explicitar modos distintos do movimento operário e fabril. E que estes movimentos sociais se caracterizariam pela heterogeneidade de seus atores, pela origem não operária de suas lideranças e da composição de seus membros, pelo repertório de ação distintos das mobilizações tradicionais do operariado fabril, pela utilização de passeatas e manifestações de massa nas ruas como forma de expressar e reivindicar suas demandas.

Em linhas gerais, os movimentos sociais que até a década de 60 do século XX eram compreendidos fundamentalmente a partir de leituras marxistas, e que se pautavam majoritariamente no estruturalismo e no funcionalismo para analisar/explicar as ações coletivas do operariado sob o par política e economia, sofreram novas configurações, sendo lidos e compreendidos à luz de uma concepção culturalista-identitária (GOHN, 2010), que passaria a enfatizar as relações micro sociais e culturais, mobilizando outras questões relacionadas à gênero, etnia, estilos de vida, meio ambiente etc.

É importante destacar nesse novo contexto teórico e conceitual, as formulações de Alain Touraine (1977), que vai ressaltar o sentido da ação dos movimentos sociais por meio da compreensão desta ação em meio de situações de conflito político. Ainda segundo este autor, devemos atribuir um olhar sobre os movimentos sociais, sobre as ações coletivas, não somente como objeto de análise, mas, também como sujeitos pertencentes a uma sociedade dinâmica, complexa, antagônica e principalmente histórica. Principalmente, porque o objeto da teoria da ação social é o sujeito histórico, Touraine (2007) defende a necessidade de um olhar dialético e dialógico para o campo empírico de análise, reconhecendo a historicidade dos diferentes sujeitos e de seus interesses manifestos. A análise desses sujeitos como ressalta Touraine, deve ser pautadas a partir de dois aspectos: o da ação coletiva e da identidade coletiva criada no processo de participação nessas ações. O autor define ação coletiva com sendo uma "ação conflitante de agentes de classes sociais lutando pelo controle do sistema de ação histórica” (1977, p.336). Essas ações 
decorrem do "confronto de interesses opostos para controlar forças de desenvolvimento e do campo de experiência histórica de uma sociedade" (1977, p. 344). Nesse sentido, Touraine (1977) ainda estabelece um modelo classificatório das ações coletivas baseado em três princípios que definiriam (ou não), se estas ações coletivas poderiam ser consideradas movimentos sociais: princípio de identidade( que seria a definição do ator por ele mesmo, construída a partir das relações sociais entre os sujeitos históricos); o princípio de oposição( no qual ator identificaria o(s) adversário(s) por meio do conflito);e o princípio da totalidade( cuja consistência se basearia no sistema de ação histórica, na qual as classes sociais disputariam entre si o controle desse sistema).

No Brasil, uma das primeiras referências a ser destacada no uso de novas abordagens e na construção de outras categorias analíticas e conceituais sobre o campo dos movimentos sociais, criticando as abordagens de cunho estruturalistas que hegemonizavam a leitura desses movimentos no final da década de 70 do século passado, foi o sociólogo Eder Sader, em seu livro "Quando novos personagens entram em cena: experiências, falas e lutas dos trabalhadores da Grande São Paulo, 1970-80", publicado em 1988.

Sader (1988) apresenta em seu livro algumas questões nodais que englobam duas categorias desses novos personagens no contexto de lutas e reivindicações: a irrupção do sujeito coletivo, social e descentralizado e as matrizes discursivas que estes vão utilizar para a leitura e a intervenção na realidade social, sobretudo pela ação coletiva em prol das conquistas de seus direitos fundamentais, como moradia, educação, transporte, trabalho, saúde, etc. Como indicador da emergência de novas identidades coletivas, este novo sujeito dos movimentos sociais se tornaria uma categoria fundamental, à medida que sua identidade e seus repertórios de ação coletiva se materializariam a partir da coletividade, através da qual os seus membros procurariam defender seus interesses e expressar suas vontades políticas, constituindo essa identidade coletiva na luta:

Ao final da década vários textos passaram a se referir à irrupção de movimentos operários e populares que emergiam com a marca da autonomia e da contestação à ordem estabelecida. Era o "novo sindicalismo", que se pretendeu independente do Estado e dos partidos; eram os "novos movimentos de bairro", que se constituíram num processo de auto-organização, reivindicando direitos e não trocando favores como os do passado; era o surgimento de uma "nova sociabilidade" em associações comunitárias onde a solidariedade e a auto-ajuda se contrapunham aos valores da sociedade e inclusiva, eram os "novos movimentos sociais", que politizavam espaços antes silenciados na esfera privada. De onde ninguém esperava, pareciam emergir novos sujeitos coletivos, que criavam seu próprio espaço e requeriam novas categorias para a sua inteligibilidade ( SADER,1988, p.35-36).

Ao reivindicar uma aproximação conceitual com as questões citadas por Sader no livro em tela, e os movimentos de luta por creche em São Gonçalo, em especial o papel do movimento ArtCreche nas lutas pelo direito à creche, venho intencionando investigar a identidade coletiva desse movimento como "sujeito histórico", isto é, busco refletir sobre a composição e interesses em disputas, tanto dos/das partícipes desse movimento, quanto dos outros atores envolvidos nas lutas por creches na cidade, tais como Prefeitura, Vereadores, Sindicatos dos Profissionais de Educação etc.

Esta questão, que em nossa compreensão exige um especial aprofundamento, será retomada na terceira parte do nosso artigo, principalmente quando referenciarmos as ações do movimento Artcreche 
na cidade, especialmente nos bairros considerados emblemáticos do descaso e abandono dos poderes públicos, tais como Salgueiro, Itaoca e Jardim Catarina.

Em linhas gerais, as questões das lutas pelos direitos sociais, pelo "direito a ter direitos" nos obriga a retomar a problemática do poder local, dos movimentos sociais e das escalas do poder nos jogos decisórios das políticas sociais e educacionais no território vivido pelas classes populares: o local. Nesse sentido, pergunto: qual o poder do poder local? Será que descentralizar competências decisórias e/ou executoras é necessariamente fortalecer a democracia? É possível conseguir respostas às demandas por direitos na forma como o Estado se relaciona com a sociedade civil? Ou o que o Estado permite é o fortalecimento de "mandonismos locais", ignorando e/ou cooptando os movimentos sociais, suas lideranças? Como a tecnocracia estatal se relaciona com estes dispositivos aparentemente voltados para o compartilhamento de poderes com a população? Qual o espaço concedido aos profissionais de educação, em especial aos educadores (as) populares das creches comunitárias nestes processos?

No presente artigo optei por enfocar a luta do ArtCreche em diálogo com autores/as que fazem alusão à eclosão dos movimentos populares na década de 1980, bem como ao seu refluxo no período de pós-democratização brasileira, tais como Sader (1988), Arroyo (2003), Daniel (1988), Gohn (2010), dentre outros. Para fins de compreensão das lutas do ArtCreche e dos cenários de implementação das políticas públicas de educação Infantil em São Gonçalo, adotamos como perspectiva de nossa análise, o conceito de poder local sugerido por Celso Daniel (1988).

Como propõe este autor, o exercício de poder não se resume ao Estado, mas está disseminado em múltiplas instituições sociais em diferentes modalidades de poder local, sendo que no Brasil, especialmente devido às formas históricas de organização e estruturação do Estado, o conceito de poder local vem sendo remetido à esfera municipal.

Tal abordagem conceitual sobre poder local articula-se à concepção de Estado conforme abordagem de Gramsci (1995), na qual também nos apoiamos, sendo este não apenas um aparelho de governo, mas, também "o aparelho privado de hegemonia ou sociedade civil". Nesse sentido, ao tratar-se da sociedade civil, esta não diz respeito apenas aos movimentos sociais populares articulados pelas classes subalternas. Dela também fazem parte diversificados grupos de interesses que estão relacionados ao poder governamental, e que também compõem o poder político local. E que travam lutas e disputas pelo acesso as suas demandas fundamentais.

Neste sentido, ao intencionar compreender a luta contemporânea do movimento ArtCreche pela expansão da Educação Infantil na cidade, busco sobretudo, complexificar o repertório de lutas pela ampliação das creches públicas nos bairros mais populosos e pobres do município. Como vem se dando a luta por creches hoje? Quem são os principais atores e quais os seus repertórios de ação? No movimento da pesquisa, venho compreendendo que estudar de forma mais aprofundada as lutas no lugar, isto é, os embates realizados nas entranhas do poder local, pode nos oferecer pistas fecundas sobre o longo e difícil processo de democratização do direito à educação, sobretudo da educação infantil de crianças das classes populares e pobres no município. 
Investigando a relação entre as escalas de poderes: $O$ poder central e poder local nas políticas para a educação as crianças das classes populares em São Gonçalo

O par poder local - poder central vem expressando uma ação política de exercício de poder que remonta ao período de nossa história colonial, em sua forma de relacionamento entre o Estado imperial português e as suas colônias, e prossegue com o advento da proclamação da República a partir da qual são firmadas as bases de pactos entre os entes federados do Brasil.

Essa ação político-administrativa forja a cultura política brasileira e sua forma de exercício do poder. A despeito da amálgama entre localismo-centralismo desde o Império, é, sobretudo, a maior potência da qual o poder local foi detentor que mereceu dedicados estudos e abertura do campo da sociologia política no Brasil.

Nesses termos, são conhecidos os clássicos trabalhos de Faoro (1995), Victor Nunes Leal (1997) e Maria Isaura de Queiróz (1976), ao analisarem o poder local, em sua forma de mandonismo, não apenas como fenômeno sociológico, mas como estrutura de padrão de dominação, tendo o coronelismo como recurso político fundamental, ao menos, de forte expressão, até a Revolução de 1930.

Nesse escopo, os estudos sobre poder local foram analisados por Daniel (1988) como sendo, ainda, embrionários, já que grande parte destes estudos, tomaram como lócus municípios que, em determinado momento de sua história, manipularam com êxito a propriedade da terra, como núcleo das origens privadas do poder público brasileiro.

A emergência de novos movimentos sociais em finais da década de 1970 e nos anos 1980 do século passado, principalmente pelos movimentos pré e pós Constituição de 1988, vem revigorando ações coletivas pelos direitos sociais e cidadania, vindo a reduzir as expectativas de segmentos sociais de que seus direitos não mais dependam da sua relação com os líderes políticos locais, instaurando, sobre novas bases, formas específicas de legitimação do poder político local. Para Daniel (1988, p. 32),

O cumprimento, pelo poder político local, de sua função de legitimação, depende então de suas posturas e atitudes em face de uma dada situação municipal, na qual combinam, com pesos diferenciados, distintas modalidades de poder social e de culturas políticas. Tal combinação é resultado, em cada município, de sua posição e função na divisão espacial do trabalho social, e sobretudo, das maneiras pelas quais seus moradores- de várias classes e grupos sociais- elaboram suas representações a respeito da sociedade e das políticas.

Mesmo com avanços da cidadania política, não se descartam as práticas clientelistas que não deixam de prosperar na esfera local, por meio do monopólio de informações que se concentra na administração pública, seja entre governo e câmara de vereadores e destes com moradores em suas bases territoriais eleitorais, seja do governo em relação aos grupos que constituem o poder político social, como por exemplo, ainda acontece cotidianamente em São Gonçalo, sobretudo ao que tange ao papel dos vereadores na distribuição clientelista (ou não) do acesso às creches públicas. 


\section{A constituição de Creches Comunitárias no Brasil e suas implicações no direito à} Educação Infantil: as lutas das mulheres do ArtCreche em São Gonçalo

Em diálogo com uma perspectiva histórica, em linhas gerais, a proliferação de creches comunitárias no Brasil ocorreu a partir da década de 1970, quando o contexto de crise econômica e deterioração das condições de vida da população favoreceram a incorporação crescente das mulheres ao mercado de trabalho, e juntamente com isso, ampliou-se a demanda por espaços de educação e cuidados de seus filhos e filhas pequenos (as). A conjuntura do período favorece, ainda, a eclosão movimentos populares, com destaque para os movimentos de mulheres e para as Comunidades Eclesiais de base $(\mathrm{CEBs})^{2}$ da Igreja Católica, cuja atuação é determinante para a formação de muitas creches comunitárias, inclusive no município de São Gonçalo.

Em nossa compreensão, as creches comunitárias mais do que uma proposta educativa à ausência de equipamentos de educação das crianças pequenas, surgiram, principalmente nas favelas e áreas pobres do Estado do Rio de Janeiro como solução para o atendimento às crianças das camadas populares em face da ausência histórica do Estado nesta área educacional. Posteriormente, em função de suas lutas e pressões muitas delas adquiriram subsídios do poder público via convênios, e via o apoio de organizações filantrópicas, tendo em vista que começam a ser tratadas como entidades sem fins lucrativos.

A principal lógica que sustentava essas ações era a expansão a baixo custo, com a exploração da mão de obra da própria comunidade para a manutenção de serviços que são de responsabilidade do Estado, visando a atender o maior número possível de crianças sem realizar investimentos compatíveis (AMMANN, 1986; ROSEMBERG, 2002).

O intuito de muitos programas era ampliar significativamente o atendimento em termos quantitativos, sem o aporte proporcional de verbas públicas, o que era viabilizado pela exploração de mão de obra voluntária ou semivoluntária das comunidades pauperizadas, leia-se favelas e áreas de ocupação popular, das quais, muitas vezes, não era exigida qualquer qualificação profissional para atuar em creches, sobretudo pela ausência histórica de um ethos profissional neste campo do trabalho educacional, bem como a sua associação com a maternagem infantil (ROSEMBERG, 2002).

Além disso, a distorção a que é submetida essa concepção de participação dos sujeitos, principalmente das mulheres nesse tipo de ações merece destaque, por conta de sua dimensão despolitizante, e muitas vezes de cooptação. A atuação dos membros da comunidade é identificada com a democratização dos processos educativos, mesmo quando o que se percebe em muitas realidades é a população local restrita ao papel de mera executora de funções e projetos, cujo processo de elaboração, a mesma sequer é (ou foi) convidada a participar.

Com as modificações que foram impetradas na Educação infantil a partir da Constituição de 1988, que tornou a educação dos "pequenos" direito das crianças, da família e dever do Estado, e posteriormente

2- As CEBs constituíram-se a partir de diferentes grupos da Igreja Católica que comungavam da chamada Teologia de Libertação, cujas intervenções tinham como público-alvo camadas da população em condição de exclusão dos bens culturais e sociais produzidos. Calcula-se que na década de 70 a 90 do século XX, cerca de 93.000 CEBs teriam sido criadas em todo o Brasil. 
com a implementação da Lei de Diretrizes e Bases da Educação Nacional (LDBEN/96), que definiu a Educação infantil como a primeira etapa da Educação Básica, além da implementação do FUNDEB, garantindo o financiamento para as creches públicas, comunitárias e filantrópicas, os convênios passaram a partir de 2004 a ser efetivados através da Secretaria de Educação, passando a ter caráter mais regulatório do que educativo, devido às inúmeras burocracias e exigências legais para o seu funcionamento.

Neste período, configuram-se na cidade duas formas de atendimento em creches: uma na qual o poder público se responsabilizava integralmente pelo atendimento em instituições públicas municipais; e outra forma na qual os investimentos são parciais e os recursos possuem forte restrição de utilização, sobretudo em relação à construção e melhorias nos espaços físicos das creches comunitárias.

Do ponto de vista territorial, São Gonçalo está dividido em 108 bairros, sendo 90 bairros oficiais e 18 reconhecidos pela população (IBGE, 2012), o que significa que, no município existem bairros subdivididos que nem sempre contam com a legitimação e o reconhecimento das instituições federais e do poder governamental local. Este é o caso do Jardim Catarina. Considerado o maior loteamento da América Latina, subdivide-se em quatro sub-bairros: Jardim Catarina Novo, Jardim Catarina Velho, Pica-Pau e Ipuca.

Vale salientar que, na grande maioria dos casos, a marca de cidadania política desses bairros é representada pelas lutas de grupos populares organizados em associações de moradores que demandam e reivindicam a implementação de políticas públicas nessas favelas, bairros e loteamentos. É justamente pelo acompanhamento do trabalho político desses grupos e associações, que vimos investigando e buscando compreender as lutas e a demanda por creches nesses territórios da cidade.

Ao inventariar essas lutas, buscando compreender os seus nexos reivindicatórios, vimos formulando questões, tais como: como tem se engendrado a atuação de movimentos e grupos de moradores do município de São Gonçalo, principalmente em questões que tangenciem o direito à educação da infância(s), seja na participação na formulação de políticas públicas para este segmento educacional, seja no sentido direto da garantia e implementação desse direito? Quais são os meios utilizados para reivindicarem e exporem suas demandas pelo direito à educação? Quais são as principais demandas desses movimentos? Quais são as repercussões das lutas desses movimentos sobre a garantia do direito em questão? Como vem se dando a recepção dos movimentos de luta por creche nos diferentes fóruns de reivindicação da cidade?

Para compreender a importância das lutas e demandas por educação Infantil em São Gonçalo, venho utilizando como fonte de estudos e pesquisas, os censos divulgados pelo Instituto Nacional de Estudos e Pesquisas Educacionais Anísio Teixeira (INEP).Esses números demonstram a evolução das matrículas em creches da rede pública entre 2004 e 2010, e além de dados disponibilizados pela SEMED/SG (2010) e pelo movimento Artcreche, os quais nos auxiliaram na compreensão do espaço ocupado pelas creches comunitárias na educação infantil do município. Porém, ainda assim, não podemos deixar de considerar que todas as formas de participação democráticas foram também conquistadas por meio de lutas históricas. E que a somente pela atuação permanente desses movimentos tem sido possível conseguir romper com a lógica do 
privilégio e da concentração de poder, produzindo fissuras nas lógicas do mandonismo local (QUEIRÓZ,1976) e conseguindo respostas efetivas às demandas pelos direitos sociais fundamentais na cidade.

Em relação aos movimentos sociais populares, mesmo diante de um período de aparente desesperança, eles permanecem em movimento. Em São Gonçalo, associações de moradores e grupos organizados, principalmente das mulheres que constituem o ArtCreche marcam presença nas sessões da câmara de vereadores, nas audiências públicas, nos fóruns dos movimentos de Educação, nos Seminários na Universidade, entre outros espaços de lutas políticas, como nas passeatas e greves convocadas pelo Sindicato dos profissionais da Educação- SEPE/SG.

Numa sociedade altamente excludente, concentradora de renda e patrimonialista como a nossa, compreendemos que as lutas que emergem desses movimentos contra-hegemônicos, e que de diferentes formas se expressam e articulam setores das classes populares, podem ampliar suas potencialidades e possibilidades, tornando-se capazes de se fazerem ouvir, pressionando de maneira ativa e crítica os processos de elaboração das políticas públicas e dos direitos fundamentais.

Neste sentido, é importante afirmar que as matrículas em creches públicas obtiveram um crescimento considerável entre 2006 e 2010, passando de 143 para 3.260, embora seja importante destacar o descumprimento das metas estipuladas pelo poder municipal no que se refere à educação infantil.

Nesse período, não houve construção de creches, mas uma escola da rede e Cieps municipalizados foram adaptados para a oferta, contrariando o que o próprio texto do Plano Municipal de Educação de São Gonçalo (PME) previa³.

O cenário é ainda mais preocupante quando se considera que, nesse período, as matrículas em creches comunitárias conveniadas com a prefeitura também não apresentaram ampliação, o que aponta um período de estagnação do atendimento, seja por meio de creches públicas, seja através de convênios.

Uma das questões de fundo que tem sido retomadas pelo conjunto de mulheres (e alguns homens) que são profissionais de creche e que atuam no Movimento ArtCreche, tem sido à dificuldade de interlocução com o Estado, principalmente com o prefeito eleito e com os membros que constituem o Conselho Municipal de Educação(CME/SG). Talvez nesse embate resida uma das questões mais importantes e desafiadoras às nossas tentativas analíticas e conceituais: quem são os sujeitos coletivos que compõem o ArtCreche? Como se representam e são representados (as) pelos demais atores em conflito e/ou alianças?

Segundo Sader (1988) poucas noções são tão ambíguas e carregadas de sutilezas quanto à noção de sujeito na modernidade ocidental. Essa ambiguidade e entendimento difuso, por exemplo, pode ser interpretado tanto na perspectiva da soberania do ator, quanto na perspectiva da sujeição do mesmo. Ainda segundo Sader, tanto no campo da filosofia, da linguística, da sociologia, passando pela psicanálise, a noção de sujeito é "um território minado, palco das mais acesas polêmicas"(1988, P.50).

Assim, quem são os "sujeitos históricos" do movimento ArtCreche? Embora não tenha a intenção de realizar este inventário semântico e conceitual da noção de sujeito, creio que o exercício de

${ }^{3}$ O Plano Municipal de Educação de São Gonçalo, aprovado em 2004, intencionou como meta a construção de, no mínimo, uma creche pública municipal por ano durante o decênio 2006-2016. Meta que não foi cumprida no período proposto. 
pensamento, colocado mesmo que ainda frágil na densidade analítica de sua interrogação, é uma fonte fértil de questões sobre o movimento e suas aspirações.

Do ponto de vista da composição dos sujeitos e da representação de sua identidade coletiva, majoritariamente o ArtCreche é constituído por mulheres na faixa etária de 25 a 50 anos, a maioria com baixa escolaridade, muitas apenas com as séries iniciais do Ensino Fundamental, sendo que a grande maioria do ponto de vista étnico-racial é negra, nascidas e criadas nos bairros pobres e populares da periferia de São Gonçalo, ou como as educadoras mais velhas, migrantes dos estados do norte e/ou do nordeste brasileiro, oriundas dos fluxos migratórios produzidos pelo capitalismo desenvolvimentista no período da ditadura militar no país.

Ainda segundo Sader e Paoli( 1986), do ponto de vista da:

(...) representação substantiva, situada e tematizada dos trabalhadores urbanos e de sua presença na sociedade brasileira (...) põe em cena a formação dos trabalhadores e de suas vidas como figuras cuja articulação tem raízes históricas na própria sociedade que se quer conhecer. Como sugere Claude Lefort, construir figuras e colocá-las em cena forma uma matriz de representação, que produz uma visão de Sociedade e é produto de uma elaboração coletiva díspare e articulada (1986, p.40).

Nesse sentido, para traçar uma cartografia, mesmo que ainda pouco consistente dos diferentes sujeitos que constituem o ArtCreche, se faz necessário situar, ainda que de forma inicial, a tradição da representação e do imaginário instituído historicamente sobre as classes populares no Brasil.

De acordo com estudos de Sader e Paoli (1986), foi no pensamento político gestado na Primeira República "que se construiu, pela primeira vez, uma representação sistemática e substantiva sobre os trabalhadores, os pobres, os dominados desta sociedade"(1986, P.44). O povo brasileiro, segundo a representação de alguns pensadores políticos mais conservadores da época, como Oliveira Vianna, Azevedo Amaral e Alberto Torres estaria fadado à "incapacidade de luta cívica”"( SADER e PAOLI, 1986).

Para esses pensadores, por conta da enorme heterogeneidade de sua composição, pelo efeito nefasto que esta heterogeneidade provocaria sobre a capacidade de ação política coletiva popular, e pela ausência crônica de aptidão para a coletividade, este povo não teria "vocação para a solidariedade e para a universalidade" (SADER e PAOLI, 1986, P.42).

Ainda segundo esses pensadores políticos da Primeira República, nada poderia ser feito a partir do povo, "pois não se tratava de povo real, com expressão representativa ordenada na Sociedade"( Idem, P.42).

Passado mais de um século da gestação e circulação dessa representação negativa, sobre a capacidade de ação política coletiva do povo brasileiro, principalmente sobre aqueles/aquelas oriundos das classes populares, nos parece fundamental arguir a atualidade dessa representação no imaginário e nas concepções concretas produzidas (e em produção) sobre a capacidade de ação e intervenção política autônoma desses sujeitos.

O quê o trabalho de campo junto ao ArtCreche tem me apresentado com dados contundentes, que falam e me obrigam à uma compreensão mais complexa das dificuldades de fissurar essa representação negativa dos movimentos sociais, é justamente o caráter de classe, de gênero e de raça desse movimento, ou seja, a sua 
interseccionalidade (MIGUEL, 2014), sendo fundamental a construção de uma análise mais complexa sobre a presença maciça de mulheres negras e invariavelmente pobres na luta por creches no Município.

Sobre o conceito de classe, reitero nessa afirmativa, em diálogo com E.P.Thompson (1987), que o conceito de classe pode ser compreendido a partir das ações dos sujeitos, e do modo como suas experiências atuais ou herdadas interferem na formação da classe. Nessa perspectiva, compreendo que embora fiel aos fundamentos da perspectiva marxiana para o estudo da classe trabalhadora inglesa, Thompson procurou articular, em um contexto histórico delimitado e profundamente estudado, "a relação entre as determinações materiais com os elementos subjetivos- no sentido de sistema de valores crenças, moral, atitudes- envolvidos no processo de articulação de identidades constituintes da consciência de classe" (MATTOS, 2012, P.84).

Na perspectiva Thompsoniana, a consciência de classe acontece:

Quando alguns homens, como resultado de experiências comuns (herdadas ou partilhadas), sentem e articulam a identidade de seus interesses entre si, e contra outros homens cujos interesses diferem (e geralmente se opõem) dos seus. A experiência de classe é determinada, em grande medida, pelas relações de produção em que os homens nasceram - ou entraram involuntariamente. A consciência de classe é a forma como essas experiências são tratadas em termos culturais: encarnadas em tradições, sistemas de valores, ideias e formas institucionais. Se a experiência aparece como determinada, o mesmo não ocorre com a consciência de classe (THOMPSON, 1987, p.9).

Embora não concorde com o uso do "masculino genérico" utilizado por Thompson para dar visibilidade às experiências de classe de homens e mulheres, reconheço a presença do "espírito da época" em sua obra, na qual a questão de gênero não era ainda uma questão nodal no reconhecimento da diversidade pela qual homens e mulheres organizam suas experiências no mundo social, e vivem a questão de classe.

Em outra perspectiva, entendo hoje, que a questão de gênero constitui um dos eixos centrais que organizam nossas experiências no mundo social mais amplo. Isso significa afirmar que, onde existem desigualdades estruturais e conjunturais que atendem a padrões de gênero, também são definidos posicionamentos relativos ao papel de mulheres e homens, ainda que a questão de gênero não possa ser compreendida de maneira isolada, mas em profunda vinculação com as questões de classe, de raça e sexualidade.

Não obstante, do ponto de vista do trabalho em creches, bem como a própria demanda e luta por esse equipamento educativo, historicamente e majoritariamente tem sido uma experiência de gênero: uma questão das mulheres. Temos clareza de que a produção dessa questão é muito mais complexa, e mereceria muito mais aprofundamento do que estamos dedicando a ela no corpo do presente artigo, porém esse aprofundamento requereria outras intencionalidades, além de outro trabalho de pensamento não previsto no escopo do artigo em tela.

Porém, com base em estudos já realizados( BIROLI, 2004, ROSEMBERG, 1986), podemos afirmar que, na cultura ocidental, sobretudo na cultura Ibérica, o cuidado com as crianças, com pessoas idosas e com as pessoas doentes tem sido uma responsabilidade e um trabalho atribuído principalmente às mulheres. Inclusive para Biroli (2004), quanto menores são os recursos e os dispositivos públicos para apoiar as pessoas e as famílias no trabalho de cuidar dos dependentes ( sejam esses crianças e /ou idosos), 
maior é o impacto e o tempo destinado das mulheres (principalmente da mulheres pobres) a essa atividade, privando-as, sobretudo, de se dedicarem ao exercício de outras atividades profissionais, e ou ao estudo e à construção de carreiras profissionais.

Mesmo que a creche seja um suporte à esfera doméstica e tenha importantes impactos na estrutura familiar, além da presença de homens como trabalhadores nesse campo profissional, e principalmente nas classes médias urbanas já existir uma maior divisão e responsabilização da família, inclusive com efetiva presença masculina, na educação da criança pequena, de 0 a 3 anos, a questão da creche ainda é fortemente associada à esfera do privado e da responsabilidade feminina.

O trabalho majoritariamente feminino realizado pelas educadoras das creches comunitárias que constituem o movimento Artcreche, expressa questões ainda pouco estudadas nos movimentos de profissionais da educação em São Gonçalo, tais como a interseccionalidade (MIGUEL, 2014) das diversas formas de opressão presente na luta dessas mulheres: questões de gênero, de raça, de classe, de desigualdade de poder simbólico pelos “efeitos do lugar"(Bourdieu, 2001) que as mesmas ocupam nos territórios da cidade, dentre outras.

A luta das educadoras do ArtCreche tem me provocado a pensar e questionar o sentido privado da educação e do cuidado com crianças pequenas, bem como o pouco valor e reconhecimento social desse trabalho, principalmente quando os sujeitos envolvidos (crianças, educadoras e familiares) são pobres, favelados(as) e majoritariamente negros(as). Neste sentido, uma das principais lutas do movimento é a produção de outra discursividade material e simbólica sobre a experiência(THOMPSON,1987) de trabalho na creche.

Subtrair a creche da esfera do privado, da esfera da "maternagem", do não-trabalho, do cuidado como um ofício feminino por natureza, do baixo valor social das atividades de cuidar, enfim, a desvalorização social do cuidado faz com que atividades a ele relacionadas sejam de modo geral, mal remuneradas.

Com relação a essas questões, Flávia Biroli (2004, P.57) nos alerta:

O treinamento social das mulheres para o cuidado com os outros e sua especialização no cuidado dos dependentes em sociedades nas quais a divisão sexual do trabalho continua a ter importância na organização das relações na esfera privada e na esfera pública as mantêm nas posições mais baixas nas hierarquias salariais e de prestígio, mesmo quando se desdobram no exercício de atividades remuneradas.

$\mathrm{Na}$ Sociedade brasileira contemporânea, as questões referentes às tarefas do cuidado, seja na creche, na casa, nos equipamentos sociais, tais como asilos, clínicas e serviços de assistência social pública e/ou de caráter filantrópico, envolve uma gama bastante complexa de questões, sobretudo, quando o trabalho de cuidar dos outros é convertido em valor monetário. Essa problemática se agudiza, especialmente quando são mulheres pobres e negras que assumem a responsabilidade das tarefas do cuidado, seja das crianças, seja dos mais velhos, pois nesse caso, como algumas mulheres que atuam no ArtCreche nos contam, como por exemplo Francisca(nome fictício), "que, mesmo trabalhando de 8 a 10 horas diárias na creche, ainda é responsável por todo o trabalho doméstico em casa, além da responsabilidade com a mãe idosa que vive com ela"( Francisca, caderno de campo, setembro de 2016). 
Assim, segundo Miguel e Biroli (2014,p.59), “a divisão sexual do trabalho e a invisibilização do trabalho não remunerado realizado por mulheres na esfera doméstica e familiar obscurecem uma dimensão importante da desigualdade de gênero", enfraquecendo as possibilidades de justiça e maior igualdade na esfera doméstica, visto que a dupla jornada de trabalho de algumas mulheres do ArtCreche, parecem ser naturalizadas por elas como parte da divisão sexual do trabalho, parte do trabalho feminino, "desde que o mundo é mundo, principalmente se a gente é pobre"(Francisca, caderno de campo, setembro de 2016).

A fala de Francisca nos remete a uma longa e renitente história de patriarcalismo, desigualdade e racismo no Brasil. O recenseamento do Império brasileiro de 1872, dezesseis anos antes da Lei Áurea, indicava que 46,67\% da população escravizada na cidade do Rio de Janeiro, já atuava nos serviços domésticos; 70\% dentre as mulheres. A abolição da escravidão não veio acompanhada de políticas reparatórias e ou de inclusão dos negros/as libertos/as. Portanto, não é natural que mais de século depois da abolição, em 1998 , que 48\% do total de mulheres negras trabalhadoras no Brasil fossem domésticas. Em 2008, 22\% das mulheres negras trabalhadoras eram domésticas. E em 2014, os índices são de 17\% de mulheres negras trabalhando como domésticas. Somente depois da PEC da Empregada Doméstica em 2013, que estabeleceu direitos trabalhista para quem trabalha mais de três dias ( 3) numa mesma casa, tais como, carteira assinada, jornada diária de oito (8) horas e quarenta e quatro semanais(44), férias remuneradas, hora extras, licença-maternidade, aviso prévio, dentro outros, que o percentual de mulheres negras no trabalho doméstico passou a apresentar alguns sinais de decréscimo, principalmente por conta do aumento das trabalhadoras domésticas denominadas "diaristas", que ampliaram a sua força de trabalho para o trabalho doméstico em várias casas, em função de não terem nenhum direito trabalhista garantido(IPEA, Retrato das Desigualdades de gênero e de raça, 2012).

Acreditamos que esse cenário, no qual a interseccionalidade das questões de classe, gênero e raça nos parece evidente, torna-se urgente de ser estudada e problematizada pelos sujeitos que constituem o ArtCreche, principalmente por possibilitar a compreensão dos mecanismos de reprodução das desigualdades econômicas e gênero na cidade, além de propiciar um debate sobre o racismo presente e silenciado no debate de quem é o / a usuário e o / a trabalhador/a das creches comunitárias e públicas do município.

Com efeito, reconhecer e estudar as lutas do ArtCreche em São Gonçalo, mesmo que ainda de forma inicial, nos remete ao desafio de reconhecer que a Sociedade civil não está em silêncio, e que suas vozes parecem ressoar mesmo que ainda não estejam sendo plenamente ouvidas. As jornadas de junho de 2013, os movimentos em disputa nas eleições presidenciais de 2014, as diferentes jornadas de lutas do MST, do MNST, do MPL, os atos dos diferentes grupos que se autodenominam apolíticos nas ruas brasileiras em março de 2015, os embates políticos de 2016, que culminaram no golpe e no impeachement da Presidenta Dilma Roussef. Hoje, em 2017, os movimentos sociais populares, mesmo na adversidade da conjuntura repressiva atual, após a finalização do golpe dado contra a frágil democracia brasileira, e a tentativa (ainda incompleta) de destruição do Partido dos Trabalhadores( PT) com uma possível e anunciada "prisão do ex-presidente Lula da Silva", 
continuam em luta nas ruas de todo o país, inclusive em São Gonçalo, parecendo confirmar que os movimentos sociais, considerados populares, ou não, estão em processo de franco recrudescimento.

$\mathrm{E}$ nos lastros desses movimentos me parece fundamental investigar e compreender, em que medidas os movimentos sociais reforçam, questionam e radicalizam os princípios da Educação Popular na contemporaneidade? E as lutas do ArtCreche, em que medida se atualizam no território? Continuam sendo uma luta (apenas) das mulheres?

Estudar esse recrudescimento das lutas por projetos em disputa, tanto ao nível de questões macro, como microssociológicas, me parece uma questão central na Educação Popular e nos movimentos sociais, sobretudo pelo caráter histórico da EP, que nasceu e se consolidou articulada aos diferentes movimentos sociais, sempre buscando uma pedagogia de luta como possibilidade de (auto) formação e de afirmação dos sujeitos populares, homens, mulheres, jovens e crianças como sujeitos políticos, autônomos, solidários e criadores de mundos no mundo.

\section{Considerações finais, embora ainda provisórias}

Como diz o outro... Que outro? E desde quando ele se chama Outro? Estranho nome, este, que não identifica, não responsabiliza, não consta de nenhum registro civil: Outro nascido em tal data, em tal lugar, do sexo masculino. Por que nunca se diz: Como diz a outra? A Outra não diz nada, limita-se a ouvir o Outro, se é que ouve? (Carlos Drummond de Andrade, 1979).

A citação utilizada como epígrafe para o fechamento (sempre provisório) do presente texto é emblemática do complexo lugar ocupado pela(s) infância(s) na contemporaneidade. Acompanhamos meio que nocauteados(as) pela velocidade das transformações cotidianas, a tensão entre os inúmeros e múltiplos discursos estruturados sobre a(s) infância(s) e as condições materiais, objetivas e subjetivas, nas quais as múltiplas infâncias concretamente se realizam, principalmente nas periferias das metrópoles capitalistas.

O escritor Carlos Drummond de Andrade em seu poema O Outro (1979) registra de maneira irônica, o fato de sempre se falar em nome do outro, sem jamais especificar quem é esse outro, observando de forma bastante irreverente que nunca se fala em nome da outra. Nesse texto, escolhemos falar da formação política dessa outra, que estamos nomeando como a educadora comunitária de periferia urbana, aquela que, apesar de "sem fala", ousa falar, se falam e são falados por nós, professoras e pesquisadoras da(s) infância(s). Buscamos no presente texto garantir a fala dessa outra, recorrendo às vozes daqueles que dialogam com elas (em estudos, pesquisas e trabalho cotidiano) e as suas próprias vozes em contextos de interação compartilhada, nas situações de pesquisa e trabalho no interior de instituições educativas.

Em São Gonçalo, município bastante populoso do Estado do Rio de Janeiro e território de nossas pesquisas interessadas, a pluralização das experiências infantis, os diferentes modos de ser criança, bem como a heterogenização da infância como categoria geracional, vem colocando questões nodais para as diferentes agências sociais reguladoras da infância, como o Estado, a família, a escola, os massmedia. No caso dos espaços de educação da pequena infância, sobretudo no interior de suas práticas cotidianas, 
amplia-se a perplexidade daqueles e daquelas que apresentam dificuldades para compreender o movediço estatuto contemporâneo da infância: os/as professores/as e demais profissionais que atuam na Educação Infantil, principalmente as educadoras que participam do movimento ArtCreche.

Deste modo, neste texto, intencionamos problematizar um conjunto de questões epistêmicas, políticas e pedagógicas derivadas de pesquisas com as educadoras e educadores que trabalham nas creches comunitárias e unidades de Educação Infantil de periferias urbanas, localizadas na cidade de São Gonçalo ${ }^{4}$, o segundo maior município em densidade populacional do Estado do Rio de Janeiro, e território físico-geográfico de (re) invenção cotidiana da(s) infância(s) que nos propomos a pesquisar e a compreender. Assim, mesmo que ainda de um modo bastante introdutório, devido à provisoriedade dos resultados de nossa pesquisa, intencionamos um diálogo com a outra, com a(s) educadoras e educadores $\mathrm{da}(\mathrm{s})$ infância(s)que nos cerca(m), e que nos demanda(m), sobretudo, atenção, escuta generosa e capacidade de compreensão.

Em nosso estudo, ainda em fase de aprofundamento, vimos confirmando que o Estado não é a expressão única de interesses dominantes, que não é impermeável às pressões advindas de outros grupos da sociedade. Estado e sociedade civil são espaços de lutas pela hegemonia ou direção político-ideológica em torno de um projeto, nos quais estão em confronto os diversos interesses. Do ponto de vista político, a hegemonia não é alcançada exclusivamente com a coerção, mas também com o consenso, conquistado nas instituições da sociedade civil, dentre as quais podemos situar as organizações populares, pois há "possibilidades de, no interior da ordem burguesa, [...] ter lugar a representação de interesses (ainda que parciais) das classes subalternas" (COUTINHO, 1989, p.54).

Atualmente no município de São Gonçalo, as relações entre o movimento de creches comunitárias ArtCreche e o poder público também envolvem o consenso ou momentos de consenso. É emblemática, nesse sentido, a formação do movimento intitulado Sindicato deCreches Comunitárias de São Gonçalo, fundado em 2010 com o intuito de afirmar uma atuação diferenciada do movimento Artcreche, cuja oposição veemente ao poder local se atribuía a pouca abertura da prefeitura às reivindicações das creches conveniadas.

A fundação do Sindicato de Creches Comunitárias, em nossa leitura, explicita a ampliação do campo de atuação da esquerda em São Gonçalo. Com efeito, com base em Bobbio(2001), definimos a esquerda como forças políticas vinculadas a partidos, sindicatos e movimentos sociais entre outros, que tendam a valorizar ações que aumentam ou reforçam a igualdade social. Nessa perspectiva, o campo da formação política das educadoras e educadores constrói-se pelos repertórios de ação política desses sujeitos. E a partir das escolhas individuais e participação nas lutas coletivas, que o campo da formação política se organiza e se consolida, oportunizando as mulheres-educadoras do ArtCreche, inúmeras possibilidades de construção de uma ação política na esfera pública, uma experiência concreta de luta política.

${ }^{4}$ O município de São Gonçalo, segundo dados do IBGE (2012), apresenta um altíssimo, acelerado e não planejado crescimento populacional. Contando com mais de noventa e dois bairros, a cidade é um retrato vivo das "desigualdades multiplicadas", expressas em seus bolsões de pobreza e violência urbana, que constrangem, principalmente, as crianças pequenas dos bairros pobres da cidade. 
Porém, como "toda relação de hegemonia (direção consensual) implica um grau maior ou menor de concessão aos interesses da classe ou grupo sobre o qual se quer exercer a hegemonia" (COUTINHO, 1989, p. 56), e se as expectativas do Sindicato não forem atendidas pelo governo local, a tentativa de formação de alianças irá se fragilizando entre os dois movimentos.

Em linhas gerais, a história da educação infantil em São Gonçalo se entrelaça e se confunde com a própria história das creches comunitárias e dos movimentos sociais da cidade, especialmente do Movimento ArtCreche.No complexo e tenso cenário do direito à educação infantil na cidade, a atual fragmentação dos movimentos de creches comunitárias poderá trazer consequênciasao atendimento de suas reivindicações. O que assistimos na atual conjuntura, em especial nas discussões do novo plano Municipal de Educação gonçalense, é uma divisão das creches comunitárias em grupos de atuação divergentes que, apesar de inúmeras convergências nas reivindicações, ainda não conseguem estabelecer pautas de lutas comuns, o que poderá fragilizá-los, amortecendo o seu poder de pressão junto aos poderes públicos em São Gonçalo. Sabemos que a falta de creches e de políticas adequadas para uma conciliação mínima ente o cotidiano do trabalho e o cuidado com as crianças pequenas penaliza as mulheres, muito mais do que os homens, principalmente em Sociedades nas quais a divisão dos papéis sociais, sexuais permanecem ainda muito vinculadas aos modelos convencionais, pautados numa certa ideologia do feminino e do masculino.

Por entendermos o papel estratégico (ideológico, geracional, cultural, sexual, educacional e político) da creche na formação integral e humana das crianças pequenas, defendemos a luta por creches como uma luta de toda a sociedade, principalmente pela possibilidade de formação de meninas e meninos que possam crescer enfrentando e produzindo outros modos de estar no mundo, sobretudo no campo da sua construção identitária e das relações de igualdade de gênero, especialmente ao que tange às formas de reprodução da vida coletiva. Lembramos que, segundo Silvia Federici(2017), a reprodução da vida na economia feminista, diz respeito a todo o trabalho necessário a reproduzir a vida, como cozinhar, lavar, limpar e cuidar. Ainda afirma a pensadora e feminista italiana (2017), que é pelas atividades de reprodução que produzimos a nossa existência, e aprendemos a cooperar, resistindo à desumanização que nos ronda, aprendendo a (re)construir o mundo como um lugar de criação, criatividade e cuidado. Para todos e todas. Mas essa já é outra história, outras vozes, outras questões de estudo.

\section{Referências}

ALONSO, A. As teorias dos Movimentos Sociais. In: Lua Nova. São Paulo, No 76, 2009.

AMMANN, S. B. Ideologia do desenvolvimento de comunidade no Brasil. São Paulo: Cortez, 1986.

ANDRADE, C.D. O Outro. IN: Poesia e Prosa. Rio de Janeiro: Nova Aguillar,1979. 
BOBBIO, N. Direita e Esquerda: Razões e Significados de uma distinção Política. $2^{a}$ Ed. São Paulo: Ed. Unesp, 2001.

BOURDIEU, P.(Coord.). A miséria do Mundo. Petrópolis: editora Vozes, 2001.

BRANDÃO, C.R. A pergunta a várias mãos: A experiência da pesquisa no trabalho do educador. São Paulo: Cortez Editora, 2003.

COUTINHO, C. N. Representação de Interesses, formulação de políticas e Hegemonia. In: TEIXEIRA, S. Reforma Sanitária: em busca de uma teoria. São Paulo: Cortez, 1989.

DANIEL, C. Poder Local - convergência entre estruturas, forças e agentes: Poder local no Brasil urbano. Revista de Estudos Regionais e Urbanos. Ano VIII, No 24, 1988.

FAORO, R. Os Donos do Poder. São Paulo: Ed. Globo, 1995.

FEDERICI, SILVIA. Calibã e a bruxa: Mulheres, o corpo e a acumulação primitiva. São Paulo: Elefante Editora, 2017.

GOHN, M. da G. Movimentos Sociais e Educação-8ª Edição. São Paulo: Cortez, 2010.

GRAMSCI, A. Concepșão dialética da bistória. Rio de Janeiro: Civilização Brasileira, 1995.

IBGE. Instituto Brasileiro de Geografia e Estatística. Rio de Janeiro, 2012.

IPEA. Instituto Econômico de Pesquisa Aplicada. Retrato das desigualdades de gênero e de raça. Brasília, Ipea, ONU Mulheres, SPM, SEPPIR, 2012.

LEAL. V,N.Coronelismo, Enxada e Voto. Rio de Janeiro: Nova Fronteira, 1997.

MATTOS, M.B. E.P. Thompson e a Tradição Crítica do Materialismo Histórico. Rio de Janeiro: Editora da UFRJ, 2012.

MELLUCCI, A. Um Objetivo para os Movimentos Sociais? IN: Lua Nova. São Paulo, No 17, 1989.

MIGUEL, L.F.; BIROLI, F.(orgs.). Feminismo e Política. São Paulo: Boitempo Editorial, 2014.

QUEIRÓZ. M,I.O Mandonismo Local na vida Politica Brasileira. São Paulo: Alfa Ômega, 1976. 
SANTOS, B. de Sousa. A Crítica da Razão Indolente, contra o Desperdício da Experiência. Porto: Edições Afrontamento, 2000.

SADER, E. Quando novos Personagens entraram em cena: experiências e lutas dos trabalhadores da Grande São Paulo 1970-1980. São Paulo: Editora Paz e Terra, 1988.

SADER, E. ; PAOLI, M.C. Sobre "Classes populares" no pensamento Sociológico Brasileiro: notas de leitura sobre acontecimentos recentes. IN: CARDOSO, R.(org.). A Aventura Antropológica: Teoria e Pesquisa. São Paulo: Editora Paz e Terra, 1988.

ROSEMBERG, F. Creches domiciliares: Argumentos on Falácias. Cadernos de pesquisa. São Paulo, $\mathrm{n}^{\circ}$ 56, fev., 1986.

. Organizações multilaterais, estado e política de educação infantil. Cadernos de pesquisa. São Paulo, $\mathrm{n}^{\circ} 115$, mar. 2002.

TARROW, S. O poder em Movimento. Petrópolis: Vozes, 2009.

THOMPSON. E.P. A Formação da Classe Operária Inglesa: a Arvore da Liberdade. Rio de janeiro: Editora Paz e Terra 1987.

TOURAINE, A. Os Movimentos Sociais. In: FORACCHI, M.; MARTINS.J.S. (Orgs.). Sociologia e Sociedade: leituras de introdução à Sociologia. Rio de Janeiro: Livros Técnicos e Científicos 1977.

Recebido em: 18/08/2017

Aprovado em: 02/12/2017 